\title{
Meningkatkan Kemampuan Berpikir Kritis Siswa dalam Tema Berbagai Pekerjaan dengan Fun thinkers
}

\section{Ni Made Upadani1 ${ }^{*}$, I Gusti Ayu Tri Agustiana²}

1,2 Program Studi Pendidikan Guru Sekolah Dasar, Universitas Pendidikan Ganesha, Singaraja, Indonesia

\section{A RT I C LE IN F O}

Article history:

Received July 26, 2021

Revised July 27, 2021

Accepted September 28, 2021

Available online August 25, 2021

Kata Kunci:

Berpikir Kritis, Media, Fun Thinkers

Keywords:

Critical Thinking, Media, Fun Thinkers

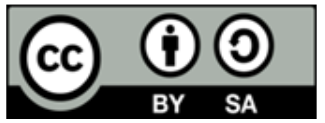

This is an open access article under the CC BY-SA license.

Copyright ( $(2021$ by Author. Published by Universitas Pendidikan Ganesha.

\begin{abstract}
A B S T R A K
Adanya kesulitan pada guru dalam merancang pembelajaran yang berpusat pada siswa sehingga membuat siswa menjadipasif dan membuat kemampuan berpikir kritas siswa tidak berkembang. Berasarkan hal tersebut diperlukan adanya media pembelajaran yang dapat mengaktifkan siswa daam pembelajaran misalnya dengan media fun thinkers. Penelitian ini bertujuan utnuk memvalidasi media fun thinkers berbasis soal berpikir kritis untuk siswa SD kelas IV pada tema 4 berbagai pekerjaan. Penelitian ini merupakan penelitian pengembangan yang dilaksanakan dengan menggunakan model ADDIE. Subjek penelitian ini adalah 2 orang dosen sebagai ahli materi, 2 orang dosen sebagai ahli media, 2 orang guru sebagai respon praktisi, dan 10 siswa sebagai respon siswa. Metode pengumpulan data yang digunakan adalah metode kuesioner dengan instrumen yang digunakan untuk mengukur tingkat validitas media fun thinkers adalah rating scale berupa lembar penilaian media fun thinkers dari ahli. Data dianalisis dengan menggunakan rumus mean untuk mengetahui rata-rata skor validitas media fun thinkers berbasis soal berpikir kritis. Penelitian ini menghasilkan media fun thinkers yang telah dinyatakan valid berdasarkan nilai rata-rata yang diperoleh dari ahli materi, ahli medi, guru, dan siswa dengan rata-rata beradada pada rentang $4.21<\mathrm{Va}<$ 5.00 dengan kualifikasi sangat valid. Berdasarkan analisis tersebut menunjukkan bahwa media fun thinkers berbasis soal berpikir kritis untuk siswa SD kelas IV tema 4 berbagai pekerjaan yang dikembangkan telah valid dan layak digunakan dalam proses pembelajaran.
\end{abstract}

\section{A B S T R A C T}

Obstacles experienced by parents in guiding children to learn can affect the low motivation and learning outcomes of students' science, especially on science content. This study aims to examine the relationship between parenting and learning motivation on student learning outcomes. This type of research is ex post facto research. The number of samples in this study was 143 students. Data collection techniques using a questionnaire. The data analysis used is simple regression and multiple regression using SPSS. The results showed that parenting, learning motivation, and learning outcomes influence each other. When described are as follows; First, there are significant results between parenting and learning outcomes obtained by the value of $F_{\text {count }}>F_{\text {table }}(0.908>0.163)$, secondly there is a significant relationship between motivation and learning outcomes obtained by the value of $F_{\text {count }}>F_{\text {table }}(0.166>0.163)$, thirdly, there is a significant relationship between the pattern nurturing and motivation on science learning outcomes obtained by the value of $F_{\text {count }}>F_{\text {table }}(0.166>0.163)$. So, there is a significant relationship between parenting patterns and learning motivation on science learning outcomes for Grade V Elementary School students separately and simultaneously. This research has an impact on improvements in the form of efforts by parents, teachers, and the community to instill a positive self-concept in children through good parenting to increase learning motivation and student learning outcomes.

\section{PENDAHULUAN}

Pendidikan merupakan suatu usaha sadar yang dilakukan oleh sesorang untuk mengembangakan kemampuan atau potensiyang dimiliinya kearah yang lebih baik lagi (Muskania \& Zulela MS, 2021; Triyani et al., 2020). Organisasi pendidikan, keilmuan dan kebudayaan (UNESCO) memberikan kontribusi yaitu dalam pendidikan didasarkan pada emapal pilar pendidikan yaitu learning to know, learning to do, learning to live together, and learning to be sehingga membuat siswa dituntut untuk mengikuti pendidikan dengan aktif (Prasetyono \& Trisnawati, 2018; Priscilla \& Yudhyarta, 2021). Sejalan dengan hal tersebut, pada kurikulum 2013 tujuan pendidikan yaitu adanya keseimbangan antara hard skill dan soft skill untuk mencakup kompetensi utama 
yang dikelompokan ke dalam tiga hal yaitu pengetahuan, sikap, dan keterampilan (Untari, 2017). Berdasarkan hal tersebut, guru memiliki peranan yang sangat penting dalam melaksanakan pembelajaran agar dapat mencapai tujuan dari pendidikan. Dalam proses pembelajaran guru memiliki tugas untuk merancang pembelajaran yang sesuai dengan tujuan dari kurikulum 2013. Dalam pembelajaran yang sesuai dengan kurikulum 2013 adalah proses pembelajaran yang menuntut siswa untuk berperan aktif dalam proses pembelajaran (Gunawan et al., 2017; Syarifudin, 2020). Salah satu cara yang dapat dilakukan untuk mengatifkan siswa dalam proses pembelajaran adalah dengan meningkatkan daya berpikir kritis siswa (Sofyan, 2019). Berpikir kritis merupakan suatu kerangka akal budi yang digunakan untuk mengalisis dalam proses mempertimbangkan atau menentukan suatu hal agar sesuai dengan logika (Agnafia, 2019; Ayçiçek, 2021). Berdasarkan hal tersebut guru perlu melakukan modifikasi dalam perancangan pembelajaran yang dapat meningkatkan daya berpikir kritis siswa. Perancangan pembelajaran tersebut dapat dilakukan dengan memilih komponen pembelajaran misalnya rencana pelakasanaan pembelajaran (RPP), media pembelajaran, buku dan lembar kerja siswa serta sarana dan prasana pendukung lainya yang dapat meningkatkan kemampuan berpikir kritis siswa (Khairunnisa, 2020; R. H. Lestari et al., 2020). Dengan melakukan perancangan pembelajaran yang baik maka akan membuat pembelajaran menjadi efektif dan menyenangkan bagi siswa serta dapat mencapai tujuan pembelajaran yang telah ditentukan dengan baik.

Namun pada kenyaaannya hal tersebut belum dapat diaksanakan dengan baik. Dalam proses pembelajaran yang guru laksanakan masih banyak yang berpusat pada guru sehingga membuat siswa kurang aktif dalam mengikuti pembelajaran (Jainuddin, 2019; Maemanah et al., 2019). Hal tersebut sesuai dengan hasil observasi yang telah dilakukan. Pada saat observasi dikehui bahwa dalam proses pembelajaran guru masih hanya berpaku pada buku pegangan dan dijelaskan langsung oleh guru. Dengan hal tersebut, maka akan membuat siswa kurang aktif dalam mengikuti pembelajaran dan dapat mengurangi kemampuan berpikir kritis siswa (Ilham \& Hardiyanti, 2020; Tias, 2017). Selain permasalahan tersebut, permaslahan lainnya yang ditemui guru dalam melaksanakan pembelajaran yaitu kesulitan dalam merancang pembelajaran yang dapat membuat siswa aktif dalam pembelajaran dan membuat siswa dapat meningkatkan kempuan berpikir siswa (Kusumaningtyas et al., 2020). permasalahan tersebut misalnya kesulitan dalam memilih media pembelajaran atau sumber belajar yang tepat. Hal tersebut sesuai dengan hasil observasiyang dlakukan dimana dalam mengajar guru tidak menggunakan media pembelajaran dikarenakan guru merasa kesualitan dalam menentukan dan merancang media pembelajaan yang sesuai. Dengan permasalahan tersebut berdampak pada siswa yang kurang termotivasi dalam mengikuti pembelajaran sehingga membuat siswa cenderung pasit dalam mengikuti pembelajaran (Babys, 2017; Fatdha \& Alamsyah, 2020). Berdasarkan hal tersebut perlu adanya solusi untuk mengatasi hal dimana pembelajaran yang berpusat pada guru dan kesulitan dalam merancang pembelajaran yang membuat siswa pasif dalam mengikuti pembelajaran dan mebuat kemampuan berpikir kritis siswa tidak berkembang.

Berdasarkan permasalahan tersebut, solusi yang dapat dilakukan adalah dengan merancang pembelajaran dengan menggunakan media pembelajaran. Media pembelajaran merupakan suatu benda, alat atau apapun itu yang dapat guru gunakan untuk membantu dalam melaksanakan pembelajaran atau membantu dalam menjelaskan materi pelajaran (Puspitarini \& Hanif, 2019; Setiawan et al., 2021). Dengan menggunakan media pembelajaran dapat dapat menarik minat siswa dalam pembelajaran sehingga membuat pemelajaran dapat berpusat pada siswa (Apriansyah et al., 2020). Berdasarkan hal tersebut, dalam memilih media pembelajaran memperhatikan beberapa hal yaitu media pembelajaran sesuai dengan karakteristik siswa, materi pembelajaran, mudah diaplikasikan dalampembelajaran dan dapat membatu siswa dalam meningkatkan kemampuannya (Yunita \& Aris Susanto, 2020). Selain itu, pemilhan media pembelajaran juga harus dapat membuat pembelajaran berpusat pada siswa atau membuat pembelajaran menarik. Salah satu media pembelajaran yang dapat menarik minat siswa dan dapat meningkatkan kemampuan berpikir krits siswa adalah media fun thinkers. Media fun thinker's merupakan seperangkat buku yang dikemas untuk menciptakan pembelajaran lebih menyenangkan. Media ini pun dilengkapi dengan sebuah alat bantu berupa papan plastik dengan 16 kotak di dalamnya yang dapat dipindahkan dari satu bagan ke bagan lainnya (Anjarani et al., 2020; Wijaya et al., 2021). Telah banyak penelitian mengenai mediafun thinkers telah dilakukan misalnya penelitian yang menyatakan bahwa media fun thinkers book yang dikembangkan dinyatakan valid dan memiliki tampilan yang dapat menarik minat siswa dalam belajar (Riani et al., 2019). Hasil penelitian yang mendapatkan hasil bahwa dengan menggunakan media fun thikers pengaruh yang signifikan terhadap pemagaman siswa dalam pembelajaran (Wijaya et al., 2021). Dengan demikian, maka dapat diyakini bahwa media fun thinker's dapat menjadi solusi atas permasalahan kurang aktifnya siswa dalam mengikuti pembelajaran. Media fun thinker's merupakan solusi yang sangat cocok untuk mengatasi permasalahan yang telah disebutkan diatas. Menggunakan media fun thinkers, diharapkan mampu untuk meningkatkan keterampilan berpikir kritis siswa dan meningkatkan keaktifan siswa dalam pembelajaran. Hal ini dikarenakan dengan menggunakan media fun thinker's siswa diajak untuk belajar sambil bermain, siswa diminta untuk menganalisis suatu gambar agar mampu menjawab dan mampu menjodohkan pertanyaan dengan jawaban yang benar. Tujuan penelitian pengembangan ini adalah untuk mengetahui proses pengembangan media fun thinkers berbasis soal berpikir 
kritis untuk siswa SD Kelas IV tema 4 berbagai pekerjaan yang telah dinyatakan valid. Pada penelitian ini, media fun thinkers dikembangakan dengan pada isi buku fun thinkers' yang dikembangakan dengan menambahkan soal-soal yang dapat mengembangkan kemampuan berpikir kritis siswa. Proses pembuatan media diawali dengan merancang desain menggunakan CorelDRAW X5, kemudian dicetak dan disusun berbentuk buku. Media fun thinker's berbasis soal berpikir kritis yang dikembangkan memiliki ukuran $21 \mathrm{~cm}$ x $29,7 \mathrm{~cm}$ dengan jumlah halaman sebanyak 36 halaman dengan 11 latihan soal. Kertas yang dijadikan bahan dalam pembuatan media fun thinker's berbasis soal berpikir kritis adalah kertas glossy dan art paper.

\section{METODE}

Penelitian ini merupakan penelitian pengembangan media pembelajaran yang dikemas dalam media fun thinkers. Penelitian ini menggunakan model penelitian ADDIE (Analyze atau analisis, Design atau desain, Development atau pengembangan, Implementation atau implementasi, Evaluation atau evaluasi). Model ini dipilih karena model ini mudah untuk digunakan dan dapat diterapkan dalam kurikulum yang mengajarkan pengetahuan, keterampilan maupun sikap seperti kurikulum yang berlaku sekarang ini yaitu Kurikulum 2013 (Molenda, 2013). Subjek pada penelitian ini adalah 2 orang dosen sebagai ahli materi dan 2 orang dosen sebagai ahli media, 2 orang guru kelas IV serta 10 siswa kelas IV di SD Negeri 2 Taro. Penelitian ini menggunakan metode kuesioner (angket). Metode kuesioner dilaksanakan dengan mengajukan beberapa pernyataan kepada responden (Agung, 2014). Penelitian ini dilakukan sampai pada uji terbatas, uji terbatas dilakukan dengan cara uji validitas media yang telah dibuat kemudian dicari respon dari guru dan siswa terhadap media yang telah diuji validitasnya. Penelitian ini menggunakan instrumen rating scale. Instrumen rating scale merupakan salah satu alat untuk memperoleh data yang berupa suatu daftar yang berisi tentang sifat atau ciri-ciri tingkah laku yang ingin diselidiki yang harus dicatat secara bertingkat. Skala penilaian yang digunakan pada rating scale adalah 1-5 (Ilhami \& Rimantho, 2017). Rating scale diperuntukkan sebagai pengumpul data hasil validitas media oleh para ahli. Kisi-kisi instrument penilaian media yang digunakan dalam penilaian initersaji pada tabel 1,2,3.

Tabel 1. Kisi-Kisi Instrumen penelitian

\begin{tabular}{ll}
\hline \multicolumn{1}{c}{ Aspek } & \multicolumn{1}{c}{ Indikator } \\
\hline Isi soal & Kejelasan dan kelengkapan identitas Kurikulum 2013 \\
& Relevansi materi soal terhadap kompetensi dasar \\
& Relevansi materi soal terhadap indikator \\
& Relevansi materi soal terhadap tingkat perkembangan siswa \\
& Relevansi materi soal \\
& terhadap muatan berpikir kritis \\
& Kualitas penggunaan bahasa \\
\hline
\end{tabular}

Tabel 2. Instrumen Ahli Media

\begin{tabular}{ll}
\hline \multicolumn{1}{c}{ Aspek } & \multicolumn{1}{c}{ Indikator } \\
\hline Desain Media & Desain sampul media \\
& Kualitas gambar yang ditampilkan \\
& Kejelasan teks yang ditampilkan \\
& Tampilan media \\
& Tata letak \\
Penggunaan bahasa & Kualitas penggunaan bahasa \\
Kemudahan penggunaan & Kemudahan penggunaan media \\
& Kejelasan penggunaan media \\
\hline
\end{tabular}

Tabel 3. Kisi-Kisi Instrumen Praktisi atau Guru

\begin{tabular}{ll}
\hline \multicolumn{1}{c}{ Aspek } & \multicolumn{1}{c}{ Indikator } \\
\hline Sajian media & Kualitas teknis media \\
& Kualitas isi materi dalam media \\
Kualitas media & Kualitas soal berbasis soal berpikir kritis \\
& Kualitas instruksional \\
\hline
\end{tabular}

Tabel 4. Instrumen Uji Perseorangan dan Kelompok Kecil

\begin{tabular}{ll}
\multicolumn{1}{c}{ Aspek } & \multicolumn{1}{c}{ Indikator } \\
\hline Materi soal & Pemahaman materi \\
Penggunaan media & Kemudahan menggunakan media dalam belajar \\
\hline
\end{tabular}


Setelah penyusunan instrument, kemudian dilakukan pengujian terhadap validasi isi instrument penilaian. Validitas isi digunakan untuk mengetahui tingkat kevalidan kisi-kisi instrumen yang disusun. Agar intrumen yang disusun dikatakan valid, maka dilakukan uji validitas isi oleh beberapa ahli (judges) yang memiliki kompetensi dari variabel yang sedang diteliti. Uji validitas dilaksanakan dengan rumus Gregory. Setelah instrumen dinyatakan valid, langkah selanjutnya adalah dilakukan uji reliabilitas. Uji reliabilitas digunakan untuk mengetahui hasil pengukuran tersebut dan tetap konsisten bila dilakukan secara berulang-ulang. Uji reliabilitas ini dilakukan oleh 2 orang ahli (judges) yang sesuai dengan bidang yang sedang diuji. Rumus yang dapat digunakan untuk uji reliabilitas adalah percentage of agreement. Di dalam penelitian pengembangan ini menggunakan metode analisis deskriptif kualitatif dan deskriptif kuantitatif. Metode analisis deskriptif kualitatif adalah suatu cara dalam menganalisis data berupa kata atau kalimat mengenai suatu objek secara sistematis dalam menghasilkan kesimpulan umum (Agung, 2014). Dalam penelitian pengembangan ini menggunakan metode analisis deskriptif kualitatif untuk mengolah data yang bersumber dari komentar, tanggapan, kritik, dan saran berdasarkan uji para ahli terhadap media yang sudah dikembangkan dengan menggunakan kuesioner atau angket. Analisis deskriptif kuantitatif merupakan sebuah cara yang digunakan untuk mengolah data dengan menyusun secara sistematis kedalam bentuk angkaangka atau persentase mengenai suatu objek yang diteliti, sehingga diperolehnya kesimpulan umum (Agung, 2014). Data pada penelitian pengemangan ini didapat melalui lembar penilaian kuesioner, kemudia data tersebut dihitung rata-ratanya sehingga akan mendapatkan hasil validitas dari media yang dikembangkan. Data tersebut dihitung dengan menggunakan rumus mean. Kriteria validitas ditentukan berdasarkan rerata skor validitas hasil penilaian pada ahli, kemudian disesuaikan dengan kriteria penilaian. Kriteria penilaian hasil validasi direpresentasikan pada Tabel 3.

Tabel 3. Kriteria Penilaian Hasil Validasi

\begin{tabular}{ccl}
\hline Interval Skor & Kategori Penilaian & \multicolumn{1}{c}{ Keterangan } \\
\hline $4,21 \leq \mathrm{Va}<5,00$ & Sangat Valid & Dapat digunakan tanpa revisi \\
$3,41 \leq \mathrm{Va}<4,20$ & Valid & Dapat digunakan dengan sedikit revisi \\
$2,61 \leq \mathrm{Va}<3,40$ & Cukup & Dapat digunakan dengan banyak revisi \\
$1,81 \leq \mathrm{Va}<2,60$ & Kurang & Belum dapat digunakan dan masih memerlukan konsultasi \\
$1,0 \leq \mathrm{Va}<1,80$ & Buruk & Belum dapat digunakan dan harus dikaji ulang serta revisi total \\
\hline & & (Pratiwi \& Andayono, 2019).
\end{tabular}

\section{HASIL DAN PEMBAHASAN}

Hasil

Tahap analisis (analyze) merupakan tahapan pertama yang dilakukan dalam penelitian ini. Pada tahap ini dilakukan dengan empat tahapan yaitu analisis kurikulum, analisis kebutuhan, analisis karateristik siswa, analisis, dan analisis media yang baik. Analisis kurikulum dilakukan dengan menganlisis KI, KD, dan Indikator yang termuat pada buku guru dan siswa tema 4 berbagai pekerjaan pada kelas IV Sekolah Dasar dan indikator keterampilan berpikir kritis yang dapat digunakan sebagai acuan dalam mengembangkan media. Hasil yang diperoleh pada analisis kurikulum yaitu pada muatan Bahasa Indonesia memuat KD yaitu menguraikan pendapat pribadi tentang isi buku sastra (cerita, dongeng, dan sebagainya. Pada muatan PPKn memuat KD yaitu menganalisis hubungan simbol dengan makna sila-sila Pancasila sebagai satu kesatuan dalam kehidupan seharihari, dan menganalisis makna hubungan simbol dengan sila-sila Pancasila. Pada muatan IPA memuat KD yaitu menganalisis pentingnya upaya keseimbangan dan pelestarian sumber daya alam di lingkungan. Pada muatan IPS memuat KD yaitu menganalisis kegiatan ekonomi dan hubungannya dengan berbagai bidang pekerjaan serta kehidupan sosial dan budaya di lingkungan sekitar sampai provinsi. Pada tahap analisis kurikulum juga diketahui keterampilan berpikir kritis meliputi memberikan penjelasan sederhana (elementery clarification), membangun keterampilan dasar (basicsupport), menyimpulkan (inference), membuat penjelasan lebih lanjut (advanced clarification), serta strategi dan taktik (strategies dan tactics). Berdasarkan hasil wawancara yang dilaksanakan dengan guru kelas IV di SD Gugus IV Tegallalang bahwa guru mengajar hanya berpatokan pada buku, sangat jarang guru menggunakan media dalam proses pembelajaran. Belum juga terdapat media yang secara khusus digunakan pada tema 4 berbagai pekerjaan di Gugus tersebut. Tidak tersedianya media yang secara khusus digunakan pada tema berbagai pekerjaan pada kelas IV membuat siswa kurang antusias dalam proses pembelajaran. Pada tahap analisis karakteristik siswa diketahui bahwa siswa SD berada pada tahap operasional konkret yang pada saat belajar memerlukan objek yang bersifat nyata atau kontekstual. Berdasarkan teori tersebut diperoleh bahwa, dalam proses pembelajaran sangat diperlukannya suatu media pembelajaran untuk siswa SD.

Tahap perencanaan (design). Tahap ini bertujuan untuk merancang media berdasarkan analsisis yang telah dilakukan sebelumnya. Proses pembuatan media diawali dengan merancang desain menggunakan CorelDRAW X5, kemudian dicetak dan disusun berbentuk buku. Media fun thinkers berbasis soal berpikir kritis yang dikembangkan memiliki ukuran $21 \mathrm{~cm}$ x 29,7 cm dengan jumlah halaman sebanyak 36 halaman dengan 11 
latihan soal. Kertas yang dijadikan bahan dalam pembuatan media fun thinkers berbasis soal berpikir kritis adalah kertas glossy dan art paper. Pada tahap ini dilakukan pengujuan validasi isi instrument penilaian dari media fun thinkers. Uji validitas instrumen dilakukan dengan memberikan instrumen yang telah disusun dan lembar penilain kepada 2 orang dosen yang ahli dalam bidang tersebut. Adapun Instrumen yang di uji validitasnya yaitu: a) instrumen validasi ahli materi, b) instrumen ahli media, c) instrumen respon praktisi, d) instrumen respon siswa. Koefisien validitas isi instrumen ahli materi diperoleh hasil 0,87 dengan kriteria validitas isi sangat tinggi. Kemudian koefisien validitas isi instrumen ahli media diperoleh hasil 0,95 dengan kriteria validitas isi sangat tinggi. Koefisien validitas isi instrumen respon praktisi diperoleh hasil 1 dengan kriteria validitas isi sangat tinggi. Koefisien validitas isi instrumen respon siswa diperoleh hasil 1 dengan kriteria validitas isi sangat tinggi. Berdasarkan kriteria valisitas isi, keempat instrumen tersebut berada pada kriteria validitas isi sangat tinggi. Setelah instrumen dinyatakan valid, selanjutnya dilakukan uji reliabilitas. Uji reliabilitas ini dilakukan oleh 2 orang ahli (judges) yang sesuai dengan bidang yang sedang diuji. Adapun instrumen yang di uji reliabilitasnya yaitu: a) instrumen validasi ahli materi diperoleh hasil 86,6\% dengan kriteria derajat reliabilitas sangat baik, b) instrumen ahli media diperoleh hasil 95\% dengan kriteria derajat reliabilitas sangat baik, c) instrumen respon praktisi diperoleh hasil 100\% dengan kriteria derajat reliabilitas sangat baik, d) instrumen respon siswa diperoleh hasil 100\% dengan kriteria derajat reliabilitas sangat baik. Berdasarkan kriteria derajat reliabilitas instrumen, hasil uji reliabilitas keempat instrumen tersebut berada pada kriteria reliabilitas sangat baik.

Tahap pengembangan yang merupakan tahapan dimana media yang dikembangkan mulai dibuat. Media yang dikembangkan terdiri dari cover, Petunjuk umum penggunaan media, KD dan indikator, prakata, daftar isi, latihan soal, daftar pustaka, dan lampiran. Adapun hasil pengembangan media fun thinkers tersaji pada gambar 1.

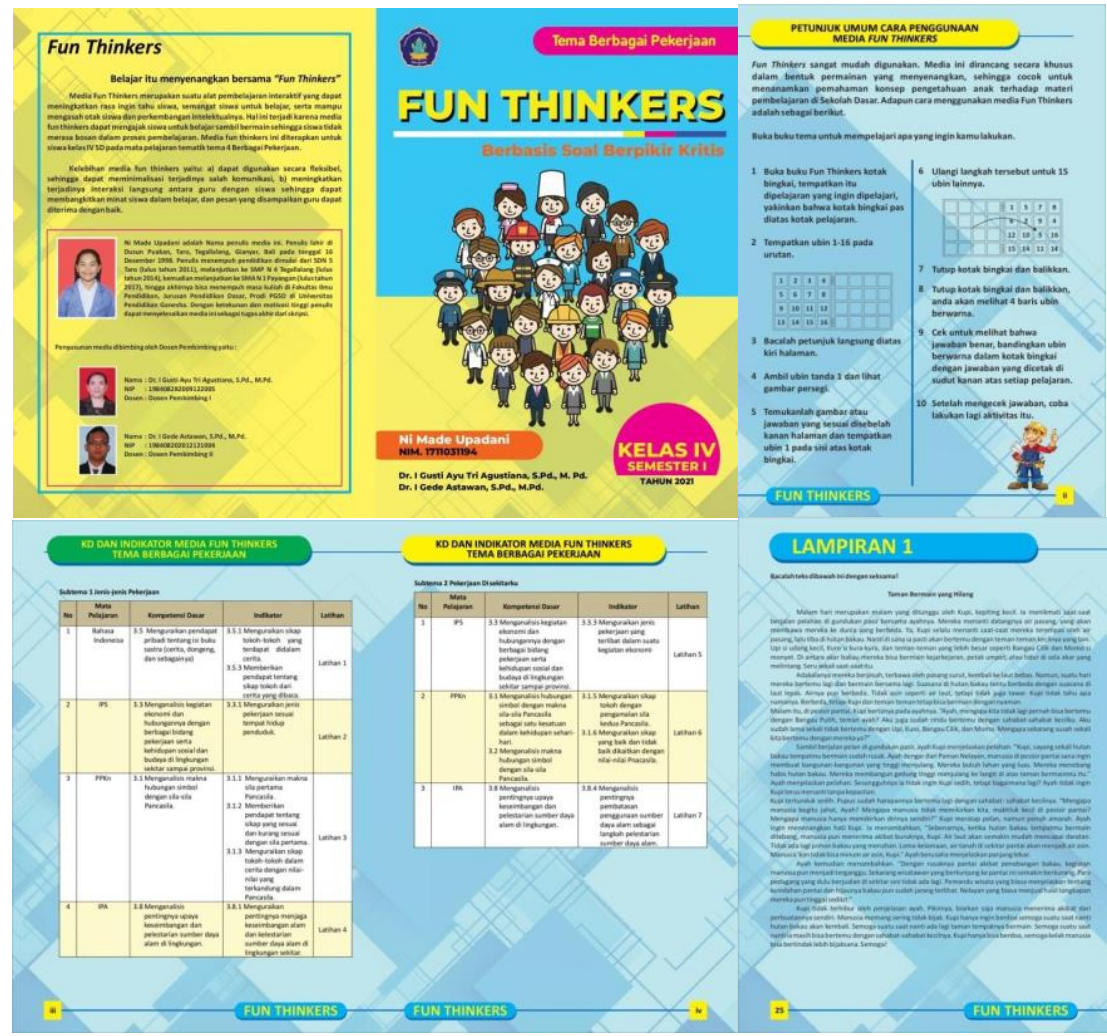

Gambar 1. Hasil Pengembangan Media Fun thinkers

Media fun thinkers yang sudah selesai dikembangkan kemudian dilakukan penilaian oleh 2 orang dosen sebagai ahli materi, 2 orang dosen sebagai ahli media, 2 orang guru sebagai respon praktisi dan 10 siswa sebagai respon siswa dengan memberikan lembar penilaian media untuk mencari validitas media fun thinkers berbasis soal berpikir kritis yang dikembangkan. Data berupa skor yang diperoleh pada lembar penilaian media kemudian dianalisis untuk mengetahui validitas media fun thinkers berbasis soal berpikir kritis. Berdasarkan hasil rerata diperoleh rentang $4.21<\mathrm{Va}<5.00$ dengan kriteria sangat valid. Hasil validitas ahli materi memperoleh rata-rata 4,93 dengan kriteria sangat valid. Hasil validitas ahli media memperoleh rata-rata 4,58 dengan kriteria sangat valid, namun perlu diperhatikan kembali pada 1 butir pernyataan yang mendapatkan penilaian dengan kualifikasi valid, yaitu kesesuaian gambar yang ditampilkan dengan latihan soal berbasis berpikir kritis sesuai pada buku tema. Hasil validitas respon praktisi memperoleh rata-rata 4,88 dengan kriteria 
sangat valid. Hasil valditas respon siswa memperoleh rata-rata 4,75 dengan kriteria sangat valid. Sedangkan hasil uji reliabilitas ahli materi memperoleh hasil $100 \%$ dengan derajat reliabilitas sangat baik. Hasil uji reliabilitas ahli media memperoleh hasil 92\% dengan derajat reliabilitas sangat baik. Hasil uji reliabilitas respon praktisi memperoleh hasil 99,5\% dengan derajat reliabilitas sangat baik. Hasil uji reliabilitas respon siswa memperoleh hasil 95\% dengan derajat reliabilitas sangat baik.

\section{Pembahasan}

Produk yang dihasilkan pada penelitian pengembangan ini adalah media fun thinkers yang berbasis berpikir kritis pada tema berbagai pekerjaan untuk kelas IV sekolah dasar. Media fun thikers dikembangakan dengan mengikuti model pengembangan $A D D I E$ namuan hanya sampai pada tahap pengembangan saja. Media yang dikembangkan terdiri dari cover, petunjuk umum penggunaan media, KD dan indikator, prakata, daftar isi, latihan soal, daftar pustaka, dan lampiran. Media fun thinkers yang dikembangkan dengan melakukan pengujian oleh para ahli media, ahli isi, praktisi atau guru dan siswa kelas IV sekolah dasar. Tahap pertama yaitu tahap analisis yang dilakukan dengan melakukan analisis kurikulum, analisis kebutuhan, analisis karateristik siswa, analisis, dan analisis media yang baik. Berdasarkan hasil analisis ditemukan permasalahan yaitu dalam proses pembelajaran khususnyapada pembelajaran tema 4 guru kurang menggunakan media pembelajaran. Hal tersebut disebakan karena ketersedian media pada tematersebut yang tidak ada dan guru merasa kesulitan dalam mengembangkan media pada tema tersebut. Permasalalah tersebut membuat siswa pasif dalam proses pembelajaran yang apabila didiamkan akan membuat siswa kuang termotivasi dalam menikuti pembelajaran dan dapat mengurangi kemampuan berpikir kritis serta hasil belajar siswa (Ilham \& Hardiyanti, 2020; Tias, 2017). Pada tahap analisis juga diketahui bahwa siswa berada pada tahap oprasional kongkrit. Sejalan dengan teori Piaget yang menyebutkan bahwa anak sekolah dasar berada pada tahap oprasional kongkrit (AD, 2018; Bujuri, 2018) yang menandakan bahwa anak akan mengerti jika diajar dengan benda kongkrit atau nyata. Hasil yang telah diperoleh kemudian dikumpulkan untuk menjadi acuan dalam proses pengembangan media.

Tahap perancangan yang dilaksanakan untuk merancang produk yang dikembangkan serta instrument penilaian validasi media. Berdasarkan pada permaslahan yang telah ditemukan pada tahap analisis maka media yang dikembangkan adalah media fun thinkers. Dengan menggunakan media fun thinkers, diharapkan mampu untuk meningkatkan keterampilan berpikir kritis siswa dan meningkatkan keaktifan siswa dalam pembelajaran. Hal ini dikarenakan dengan menggunakan media fun thinkers siswa diajak untuk belajar sambil bermain, siswa diminta untuk menganalisis suatu gambar agar mampu menjawab dan mampu menjodohkan pertanyaan dengan jawaban yang benar. Poin yang dikembangkan dalam media fun thinkers adalah pada isi buku fun thinkers. Proses pembuatan media diawali dengan merancang desain menggunakan CorelDRAW X5, kemudian dicetak dan disusun berbentuk buku. Media fun thinkers berbasis soal berpikir kritis yang dikembangkan memiliki ukuran 21 cm x 29,7 cm dengan jumlah halaman sebanyak 36 halaman dengan 11 latihan soal. Kertas yang dijadikan bahan dalam pembuatan media fun thinkers berbasis soal berpikir kritis adalah kertas glossy dan art paper. Pada tahap ini juga dilaksanakan penyususan instrument penilaian media yang akan digunakan. Instrument yang disusun kemudian dilakukan pengujian validitas isi dan reabilitasnya. Tujuan dilakukan pengujian valitas isi dan reabilitas adalah untuk menyatakan instrument yang digunakan dapat dinyatakan baik digunakan karena instrument valid dan apabila digunakan terus menerus hasilnya tidak berubah-ubah atau sama. Berdasarkan hasil pengujian instrument yang dilakukan oleh 2 orang judges diketahui bahwa istrumen dinyakan valid dan layak digunakan untuk menilai media yang dikembangkan.

Tahap pengembangan yang dilakukan untuk membuat media yang telah dirancang sebelumnya menjadi media sesungguhnya dan telah teruji validitanya. Media yang telah dibuat kemujian dilakukan uji validasi yang dilakukan oleh 2 orang ahli media, 2 orang ahli isi, 2 orang guru atau praktisi, dan 10 orang siswa. Berdasarkan hasil yang telah diperoleh, media fun thinkers yang berbasis berkipikir kritis dinyatakan valid dan layak digunakan dalam pembelajaran khususnya padapembelajartan tema 4 tentang berbagai pekerjaan. Kelayakan media fun thinkers yang telah dikembangkan dapat dilihat dari dua aspek yaitu aspek isi dan aspek media. Dilihat dari aspek isi, kelayakan media fun thinkers yang dikembangkan memiliki isi yang dilengkapi dengan soal atau latihan yang dapat meningkatkan kemampuan berpikir kritis siswa. Keterampilan berpikir kritis sangat penting untuk siswa, dikarenakan dengan siswa memiliki keterampilan berpikir kritis akan membuat siswa dapat menyelesaikan masalah sosial, keilmuan dan permasalahan praktis secara efektif sehingga dapat menolong siswadalam mengembangkan dirinya (Lestari et al., 2017; Redhana, 2013). Dengan menambahkan usur berpikir kritis pada media pembelajaran akan membuat siswa memiliki memiliki kemampuan menganalisis dan memberikan tanggapan terhadap informasi secara tepat (Nadeak et al., 2020; Zulhelmi et al., 2017). Kelayakan media fun thinkers juga dapat dilihat dari aspek media yang didesain dengan system pembelajaran sambila bermain. Pembelajaran sambil bermain akan membuat siswa aktif dalam mengikuti pembelajaran (Jundu et al., 2019; Saputri et al., 2018). Selain itu, media yang dikembangkan telah disesuaikan dengan karakteristik siswa sekolah dasar yang berdasa pada tahap oprasional kongkrit (Ananda, 2018; Hikmawati, 2018). Dengan menggunakan media yang dapat memberikan penjelasan kepada siswa secara kongkrit akan memudahkan siswa dalam memahami materi (Asmara et al., 2018; Hilmy \& Niam, 2020). Hasil 
yang telah diperoleh sejalan dengan hasil penelitian yang dilakukan oleh (Riani et al., 2019) media fun thinkers book yang dikembangkan dinyatakan valid dan memiliki tampilan yang dapat menarik minat siswa dalam belajar. Hasil penelitian yang menyatakan hasil bahwa dengan menggunakan media fun thikers pengaruh yang signifikan terhadap pemagaman siswa dalam pembelajaran (Wijaya et al., 2021). Berdasarkan hal tersebut maka dapat diyakini bahwa media fun thinker's dapat menjadi solusi atas permasalahan kurang aktifnya siswa dalam mengikuti pembelajaran.

Berdasarkan hasil yang telah diperolehdan dengan didukung oleh penelitian yang relevan maka dapat diketahui bahwa media fun thinkers yang dikembangkan layak digunakan dalam pembelajaran dikarenakan media fun thinkers mampu untuk meningkatkan keterampilan berpikir kritis siswa dan meningkatkan keaktifan siswa dalam pembelajaran. Dengan menggunakan media fun thinkers siswa diajak untuk belajar sambil bermain, siswa diminta untuk menganalisis suatu gambar agar mampu menjawab dan mampu menjodohkan pertanyaan dengan jawaban yang benar, sehingga akan membuat siswa aktif dalam mengikuti pembelajaran. Implikasi dari penelitian ini adalah dengan adanya media ini diharapkan dapat memfasislitasi siswa dalam proses pembelajaran, sehingga tujuan dari pembelajaran bisa tercapai dengan optimal. Kehadiran media fun thinkers berbasis soal berpikir kritis untuk siswa SD kelas IV pada tema 4 berbagai pekerjaan diharapkan dapat meningkatkan semangat siswa untuk mengikuti proses pembelajaran dengan baik karena dengan menggunakan media ini siswa dapat belajar sambil bermain. Dengan adanya media fun thinker's berbasis soal berpikir kritis dapat membantu siswa dalam melatih dan mengasah kemampuan berpikir kritis siswa karena dalam media ini disajikan soal-soal berbasis berpikir kritis. Berdasarkan pada hasil penelitian yang telah dilakukan maka media fun thiker memiliki banyak kelebihan. Kelebihan dari penelitian ini adalah adanya media fun thinkers berbasis soal berpikir kritis dapat membantu siswa dalam melatih dan mengasah kemampuan berpikir kritis siswa karena dalam media ini disajikan soal-soal berbasis berpikir kritis (Bustami et al., 2018; Noviyanti et al., 2019). Selain itu, adanya media fun thinkers dapat meningkatkan semangat siswa untuk mengikuti proses pembelajaran dengan baik karena dengan menggunakan media ini siswa dapat belajar sambil bermain (Akmal et al., 2020; Pham et al., 2020). Selain kelebihan yang telah disampaikan, kelemahan dalam penelitian pengembangan ini adalah media fun thinkers' yang telah dikembangkan masih hanya terpaku pada materi pada satu tema saja yaitu tema 4 tentang berbagai pekerjaan saja, sehingga dirapkan untuk terdapat penelitian yang serupa namun mencangkup materi yang lebih luas lagi

\section{SIMPULAN}

Berdasarkan hasil yang telah dan pembahasan maka dapat disimpulkan bahwa pada penelitian ini dihasilkan media fun thinkers yang berbasis berpikir kritis pada tema berbagai pekerjaan untuk kelas IV sekolah dasar. Media fun thinkers yang telah dikembangkan dinyatakan valid berdasarkan hasil penilaian oleh ahli media, ahli isi, praktisi, dan siswa. Berdasarkan hal tersebut maka dapat diyakini bahwa media fun thinkers dinyatakan layak digunakan dalam pembelajaran tematik khususnya pada tema berbagai pekerjaan kelas IV sekolah dasar.

\section{DAFTAR PUSTAKA}

AD, Y. (2018). Konsep Perkembangan Kognitif Perspektif Al-Ghazali Dan Jean Piaget. KONSELI: Jurnal Bimbingan dan Konseling (E-Journal), 5(2), 97. https://doi.org/10.24042/kons.v5i2.3501.

Agnafia, D. N. (2019). Analisis Kemampuan Berpikir Kritis Siswa dalam Pembelajaran Biologi. Florea: Jurnal Biologi dan Pembelajarannya, 6(1), 45. https://doi.org/10.25273/florea.v6i1.4369.

Agung, A. A. G. (2014). Metodologi Penelitian Pendidikan. Deepublish.

Akmal, S., Masna, Y., Tria, M., \& Maulida, T. A. (2020). EFL Teachers' Perceptions: Challenges and Coping Strategies of Integrated Skills Approach (ISA) Implementation at Senior High Schools in Aceh. IJELTAL (Indonesian Journal of English Language Teaching and Applied Linguistics), 4(2), 363. https://doi.org/10.21093/ijeltal.v4i2.522.

Ananda, R. (2018). Penerapan Pendekatan Realistics Mathematics Education (Rme) Untuk Meningkatkan Hasil Belajar Matematika Siswa Sekolah Dasar. Jurnal Cendekia : Jurnal Pendidikan Matematika, 2(1), 125-133. https://doi.org/10.31004/cendekia.v2i1.39.

Andriawan, A. (2015). Pengembangan Media Pembelajaran Berbasis Video Demonstrasi Pada Mata Pelajaran Praktik Batu Kelas XI Jurusan Teknik Konstruksi Batu Beton di SMKN 2 Pengasih. Jurnal Pendidikan Teknik Sipil Dan Perencanaan. E-Journal Pend. Teknik Sipil Dan Perencanaan, 3(3), 1-7. https://doi.org/http://eprints.uny.ac.id/id/eprint/21282.

Anjarani, A. S., Mulyadiprana, A., \& Respati, R. (2020). Fun Thikers sebagai Media Pembelajaran untuk Siswa Sekolah Dasar: Kajian Hipotetik. PEDADIDAKTIKA: Jurnal Ilmiah Pendidikan Guru Sekolah Dasar, 7(4), 100-111. https://ejournal.upi.edu/index.php/pedadidaktika/article/view/26466.

Apriansyah, M. R., Sambowo, K. A., \& Maulana, A. (2020). Pengembangan Media Pembelajaran Video Berbasis Animasi Mata Kuliah Ilmu Bahan Bangunan di Program Studi Pendidikan Teknik Bangunan Fakultas 
Teknik Universitas Negeri Jakarta. Jurnal PenSil, 9(1), 9-18. https://doi.org/10.21009/jpensil.v9i1.12905.

Asmara, Y. P., Kurniawan, T., Sutjipto, A. G. E., \& Jafar, J. (2018). Application of plants extracts as green corrosion inhibitors for steel in concrete - A review. Indonesian Journal of Science and Technology, 3(2), 158-170. https://doi.org/10.17509/ijost.v3i2.12760.

Ayçiçek, B. (2021). Integration of critical thinking into curriculum: Perspectives of prospective teachers. Thinking Skills and Creativity, 41, 100895. https://doi.org/10.1016/j.tsc.2021.100895.

Babys, U. (2017). Kemampuan Literasi Matematis Space And Shape Dan Kemandirian Siswa SMA Pada Discovery Learning Berpendekatan RME-PISA. JPMI (Jurnal Pendidikan Matematika Indonesia), 1(2), 43. https://doi.org/10.26737/jpmi.v1i2.82.

Bujuri, D. A. (2018). Analisis Perkembangan Kognitif Anak Usia Dasar dan Implikasinya dalam Kegiatan Belajar Mengajar. LITERASI (Jurnal Ilmu Pendidikan), 9(1), 37. https://doi.org/10.21927/literasi.2018.9(1).3750.

Bustami, Y., Syafruddin, D., \& Afriani, R. (2018). The implementation of contextual learning to enhance biology students' critical thinking skills. Jurnal Pendidikan IPA Indonesia, 7(4), 451-457. https://doi.org/10.15294/jpii.v7i4.11721.

Fatdha, S. E., \& Alamsyah, M. (2020). Penerapan Metode Student Teams Achievement Division (STAD) dalam Media Pembelajaran Multimedia Kreatif. Jurnal Teknologi Dan Open Source, 3(2), 284-297. https://doi.org/10.36378/jtos.v3i2.807.

Giyanti. (2018). Pengaruh Model Pembelajaran Kooperatif Student Teams Achievment Devision (STAD) dan Rasa Percaya Diri Siswa terhadap Hasil Belajar Matematika Siswa SMA. GAUSS: Jurnal Pendidikan Matematika, 1(1), 37. https://doi.org/10.30656/gauss.v1i1.635.

Gunawan, I., Ulfatin, N., Sultoni, S., Sunandar, A., Kusumaningrum, D. E., \& Triwiyanto, T. (2017). Pendampingan Penerapan Strategi Pembelajaran Inovatif dalam Implementasi Kurikulum 2013. Abdimas Pedagogi, 1(1), 37-47. https://doi.org/http://dx.doi.org/10.17977/um050v1i1p\%25p.

Hikmawati, N. (2018). Analisa kesiapan kognitif siswa SD/MI. Kariman, 6(1), 109-128. https://doi.org/10.52185/kariman.v6i1.15.

Hilmy, M., \& Niam, K. (2020). Winning the Battle of Authorities: The Muslim Disputes Over the Covid-19 Pandemic Plague in Contemporary Indonesia. QIJIS (Qudus International Journal of Islamic Studies), 8(2), 293. https://doi.org/10.21043/qijis.v8i2.7670.

Ilham, M., \& Hardiyanti, W. E. (2020). Pengembangan Perangkat Pembelajaran Ips Dengan Metode Saintifik Untuk Meningkatkan Kemampuan Berpikir Kritis Siswa Materi Globalisasi Di Sekolah Dasar. Jurnal Ilmiah Pendidikan Dasar, 7(1), 12. https://doi.org/10.30659/pendas.7.1.12-29.

Ismail, M. E., Utami, P., Ismail, I. M., Hamzah, N., \& Harun, H. (2018). Development of massive open online course (MOOC) based on addie model for catering courses. Jurnal Pendidikan Vokasi, 8(2), 184. https://doi.org/10.21831/jpv.v8i2.19828.

Jainuddin. (2019). Peningkatan Hasil Belajar Matematika Melalui Latihan Menyelesaikan Soal Secara Sistematis Pada Siswa Kelas XI. IPA 1 SMA Negeri 2 Sungguminasa. Klasikal: Journal of Education, Language Teaching and Science, 1(3), 44-52. https://doi.org/10.52208/klasikal.v1i3.42.

Jundu, R., Jehadus, E., Nendi, F., Kurniawan, Y., \& Men, F. E. (2019). Optimalisasi Media Pembelajaran Interaktif dalam Meningkatkan Kemampuan Matematis Anak di Desa Popo Kabupaten Manggarai. E-Dimas: Jurnal Pengabdian kepada Masyarakat, 10(2), 221. https://doi.org/10.26877/e-dimas.v10i2.3353.

Khairunnisa, I. S. J. (2020). Analisis Metode Pembelajaran Komunikatif Untuk Ppkn Jenjang Sekolah Dasar. ELSE (Elementary School Education Journal), 1(1), 1-7. http://dx.doi.org/10.30651/else.v4i1.3970.

Kusumaningtyas, R., Sholehah, I. M., \& Kholifah, N. (2020). Peningkatan Kualitas Pembelajaran Guru Melalui Model dan Media Pembelajaran bagi Generasi Z. Warta LPM, 23(1), 54-62. https://doi.org/10.23917/warta.v23i1.9106.

Lestari, D. D., Ansori, I., \& Karyadi, B. (2017). Penerapan Model Pbm Untuk Meningkatkan Kinerja Dan Kemampuan Berpikir Kritis Siswa Sma. Diklabio: Jurnal Pendidikan dan Pembelajaran Biologi, 1(1), 4553. https://doi.org/10.33369/diklabio.1.1.45-53.

Lestari, R. H., Sumitra, A., Nurunnisa, R., \& Fitriawati, M. (2020). Perancangan Perencanaan Pembelajaran Anak Usia Dini Melalui Sistem Informasi Berbasis Website. Jurnal Obsesi : Jurnal Pendidikan Anak Usia Dini, 5(2), 1396-1408. https://doi.org/10.31004/obsesi.v5i2.770.

Maemanah, S., Suryaningsih, S., \& Yunita, L. (2019). Kemampuan Pemecahan Masalah Melalui Model Flipped Classroom Pada Pembelajaran Kimia Abad Ke 21. Orbital: Jurnal Pendidikan Kimia, 3(2), 143-154. https://doi.org/10.19109/ojpk.v3i2.4901.

Muskania, R., \& Zulela MS. (2021). Realita Transformasi Digital Pendidikan di Sekolah Dasar Selama Pandemi Covid-19. Jurnal Pendidikan Dasar Nusantara, 155-165. https://doi.org/10.29407/jpdn.v6i2.15298.

Nadeak, B., Juwita, C. P., Sormin, E., \& Naibaho, L. (2020). Hubungan kemampuan berpikir kritis mahasiswa 
dengan penggunaan media sosial terhadap capaian pembelajaran pada masa pandemi Covid-19. Jurnal Konseling dan Pendidikan, 8(2), 98. https://doi.org/10.29210/146600.

Noviyanti, E., Rusdi, R., \& Ristanto, R. H. (2019). Guided Discovery Learning Based on Internet and Self Concept: Enhancing Student's Critical Thinking in Biology. Indonesian Journal of Biology Education, 2(1), 7-14. https://doi.org/10.31002/ijobe.v2i1.1196.

Pham, V. H., Cichy, I., Wawrzyniak, S., \& Rokita, A. (2020). "BRAINballs" educational balls - An innovative teaching method in education "Children learn while playing." VNU Journal of Science: Education Research, 36(4), 68-74. https://doi.org/10.25073/2588-1159/vnuer.4443.

Prasetyono, R. N., \& Trisnawati, E. (2018). Pengaruh Pembelajaran IPA Berbasis Empat Pilar Pendidikan terhadap Kemampuan Berpikir Kritis. JIPVA (Jurnal Pendidikan IPA Veteran), 2(2), 162. https://doi.org/10.31331/jipva.v2i2.679.

Pratiwi, D. S., \& Andayono, T. (2019). Persepsi Mahasiswa Program Studi Pendidikan Teknik Bangunan Terhadap Penggunaan E-Learning. Cived, 6(4). https://doi.org/10.24036/cived.v6i4.106894.

Priscilla, C., \& Yudhyarta, D. Y. (2021). Implementasi Pilar-Pilar Pendidikan UNESCO. Asatiza: Jurnal Pendidikan, 2(1), 64-76. https://doi.org/10.46963/asatiza.v2i1.258.

Puspitarini, Y. D., \& Hanif, M. (2019). Using Learning Media to Increase Learning Motivation in Elementary School. Anatolian Journal of Education, 4(2), 53-60. https://doi.org/10.29333/aje.2019.426a.

Redhana, I. W. (2013). Model Pembelajaran Berbasis Masalah dan Pertanyaan Socratik untuk Meningkatkan Keterampilan Berpikir Kritis Siswa. Jurnal Cakrawala Pendidikan, 3, 351-365. https://doi.org/10.21831/cp.v0i3.1136.

Riani, R. P., Huda, K., \& Fajriyah, K. (2019). Pengembangan Media Pembelajaran Tematik "Fun thinkers Book" Tema Berbagai Pekerjaan. Jurnal Sinektik, 2(2), 173-184. https://doi.org/10.33061/js.v2i2.3330.

Saputri, D. Y., Rukayah, \& Indriayu, M. (2018). Need Assessment of Interactive Multimedia Based on Game in Elementary School: A Challenge into Learning in 21st Century. International Journal of Educational Research Review, 3(3), 1-8. https://doi.org/10.24331/ijere.411329.

Saroh, I. (2016). Pengembangan Media Flash CardFun thinkers Tematik Sebagai Pendukung Pembelajaran Saintifik Pada Siswa Kelas II SD N Karang Tempel: Vol. III (Nomor 2). Universitas PGRI Semarang.

Setiawan, B., Pramulia, P., Kusmanarti, D., Juniarso, T., \& Wardani, I. S. (2021). Peningkatan Kompetensi Guru Sekolah Dasar Dalam Pengembangan Bahan Ajar Daring di SDN Margorejo I Kota Surabaya. MANGGALI: Jurnal Pengabdian dan Pembelajaran Masyarakat, $1(1), \quad$ 46-57. https://doi.org/10.31331/manggali.v1i1.1547.

Sofyan, F. A. (2019). Implementasi Hots Pada Kurikulum 2013. Inventa, 3(1), 1-9. https://doi.org/10.36456/inventa.3.1.a1803.

Syarifudin, A. S. (2020). Impelementasi Pembelajaran Daring Untuk Meningkatkan Mutu Pendidikan Sebagai Dampak Diterapkannya Social Distancing. Jurnal Pendidikan Bahasa dan Sastra Indonesia Metalingua, 5(1), 31-34. https://doi.org/10.21107/metalingua.v5i1.7072.

Tias, I. W. U. (2017). Penerapan Model Penemuan Terbimbing Untuk Meningkatkan Hasil Belajar Ipa Siswa Sekolah Dasar. DWIJA CENDEKIA: Jurnal Riset Pedagogik, 1(1), 50-60. https://doi.org/10.20961/jdc.v1i1.13060.

Triyani, E., Busyairi, A., \& Ansori, I. (2020). Penanaman Sikap Tanggung Jawab Melalui Pembiasaan Apel Penguatan Pendidikan Karakter Siswa Kelas Iii. Jurnal Kreatif: Jurnal Kependidikan Dasar, 10(2), 150154. https://doi.org/10.15294/kreatif.v10i2.23608.

Untari, E. (2017). Pentingnya Pembelajaran Multiliterasi untuk Mahasiswa Pendidikan Guru Sekolah Dasar dalam Mempersiapkan Diri Menghadapi Kurikulum 2013. Wahana Sekolah Dasar, 25(1), 16-22. https://doi.org/10.17977/um035v25i12017p016.

Wijaya, I. H., Ermiana, I., \& Khair, B. N. (2021). the Influence of Fun thinkers Book Media Towards Science Concepts Understanding of 5Th Grade Student on Min 3 Central Lombok in 2020/2021 Academic Year. Progres Pendidikan, 2(2), 81-88. https://doi.org/10.29303/prospek.v2i2.128.

Yunita, \& Aris Susanto. (2020). Merancang Media Pembelajaran Berbasis Web Menggunakan Aplikasi Dreamweaver Pada SMAN 1 Kapoiala. Simkom, 5(2), 9-18. https: //doi.org/10.51717/simkom.v5i2.43.

Zulhelmi, Adlim, \& Mahidin. (2017). Pengaruh Media Pembelajaran Interaktif Terhadap Peningkatkan Keterampilan Berpikir Kritis Siswa. Jurnal Pendidikan Sains Indonesia (Indonesian Journal of Science Education), 5(1), 72-80. 